\title{
AS AÇÕES DE GESTÃO DO CONHECIMENTO PARA A CONSTRUÇÃO DA CARREIRA PROFISSIONAL NA ASSOCIAÇÃO BRASILEIRA DE RECURSOS HUMANOS DO RIO GRANDE DO SUL
}

\section{Emille Prates Gonçalves}

Bacharela em Administração. Centro Universitário Metodista. emilleprates@gmail.com

\section{Maria D'Lourdes Rotermund}

Mestre em Administração. Centro Universitário Metodista.

maria.rotermund@metodistadosul.edu.br.

\section{RESUMO}

A gestão do conhecimento busca valorizar seus bens intangíveis, ou seja, seus profissionais por meio de práticas e processos que fomentem a criação e compartilhamento de conhecimento para todos os níveis da organização. Através das ações de gestão do conhecimento, a empresa colabora com o desenvolvimento da instituição, das pessoas e por consequência de sua carreira profissional. Para enfrentar um mercado competitivo é necessário gerir seus ativos intangíveis de maneira eficaz e, se utilizar do conhecimento da organização de uma maneira estratégica, pode levar à uma vantagem competitiva de mercado. Este trabalho tem como objetivo identificar a contribuição das ações de gestão do conhecimento na Associação Brasileira de Recursos Humanos do Rio Grande do Sul na construção da carreira profissional de seus colaboradores. Para alcançar os objetivos propostos, o método de pesquisa utilizada foi o estudo de caso. Foram levantados dados primários, através de entrevista com quatro gestores e aplicação de um questionário com colaboradores da organização. Também se utilizou de dados secundários, por meio de pesquisa documental e bibliográfica. Através da análise interpretativa, pode se descrever as práticas de gestão do conhecimento utilizadas na organização, discutir 
e averiguar junto aos colaboradores da ABRH-RS a importância das ações de gestão de conhecimento para a construção da carreira profissional. Os funcionários da instituição percebem valor e consideram como desenvolvimento profissional as ações promovidas como: treinamentos, reuniões, mentoria e narrativas. Embora eles apontam que o conhecimento seja em partes disseminado na empresa, a empresa investe em treinamentos e estimula as práticas de gestão do conhecimento, mas a organização ainda não tem a cultura de documentar todos os processos de ações de conhecimento que utiliza, e isto, pode ocasionar em perda de informação que é essencial para a geração de conhecimento no futuro.

PALAVRAS-CHAVE: Gestão. Conhecimento. Carreira.

\section{THE KNOWLEDGE MANAGEMENT ACTIONS FOR THE CONSTRUCTION OF PROFESSIONAL CAREERS IN THE BRAZILIAN HUMAN RESOURCES ASSOCIATION OF RIO GRANDE DO SUL}

\section{ABSTRACT}

Knowledge management seeks to value its intangible assets, that is, its professionals through practices and processes that foster the creation and sharing of knowledge for all levels of the organization. Through the actions of knowledge management, the company collaborates with the development of the institution, the people and the consequence of their professional career. In order to face a competitive market it is necessary to manage its intangible assets in an effective way, and if, using the knowledge of the organization in a strategic way, it can lead to a competitive market advantage. This paper aims to identify the contribution of knowledge management actions in the Brazilian Association of Human Resources of Rio Grande do Sul in the construction of the professional career of its collaborators. To reach the proposed objectives, the research method used was the case study. Primary data were collected through an interview with four managers and application of a questionnaire with employees of the organization. We also used secondary data, through documentary and bibliographic research. Through the interpretative analysis, it is possible to describe the knowledge management practices used in the organization, to discuss and to ascertain, together with ABRH-RS employees, the importance of knowledge management actions to build a professional 
career. The employees of the institution perceive value and consider as professional development the actions promoted as: trainings, meetings, mentoring and narratives. Although they point out that knowledge is in widespread parts in the company. The company invests in training and stimulates knowledge management practices, but the organization still does not have the culture to document all the processes of knowledge actions that it uses, and this, can cause in information loss that is essential for the generation of knowledge in the future.

KEYWORDS: Management. Knowledge. Career.

\section{INTRODUÇÃO}

Com as permanentes transformações, no universo corporativo, a gestão do conhecimento ganha força a partir do momento em que é elevada ao patamar de diferencial competitivo nas organizações. No passado as máquinas e atividades operacionais eram as fontes de lucratividade, mas no mundo contemporâneo o capital intelectual é reconhecido como gerador principal de resultados e diferencial competitivo. São as pessoas que detém o conhecimento e o principal desafio das instituições é saber gerenciar esse conhecimento. Neste contexto, Trindade et al. (2015) afirmam que, embora não exista uma definição única de gestão do conhecimento, a mesma se trata de um processo através do qual as organizações geram valor a partir de seus ativos intelectuais e base de conhecimento.

Segundo Ricardo (2007), as empresas estão utilizando mais o conhecimento e menos os ativos mobilizados como fontes geradoras de riquezas. Elas estão potencializando o reconhecimento do ser humano e de suas habilidades emocionais e criativas, tornando-se mais competitivas no mercado.

Para Veloso, Silva e Dutra (2012), as empresas desempenham uma função significativa em fornecer recursos para que as carreiras de seus profissionais se desenvolvam. Seguindo esta linha de raciocínio, Gramigna (2002) expõe que, com as constantes transformações no mundo corporativo, faz-se necessário uma atenção maior dos gestores de pessoas em formar e 
manter seu capital intelectual a fim de evitar a evasão de seus colaboradores, pois as empresas bem sucedidas investem nos recursos humanos e os consideram peças chaves, responsáveis pelo sucesso ou não da empresa.

De acordo com Dutra $(2009 ; 2013)$, as organizações vêm desafiando seus funcionários a planejarem suas carreiras por diversos motivos. Ele menciona que os indivíduos devem ter um espírito empreendedor consigo mesmos. Ainda o autor expõe que, as pessoas ao planejarem suas carreiras, pensam no seu desenvolvimento particular, criando subsídios para negociarem com a empresa. Além disso, as modificações na maneira de gerenciar as pessoas têm apontado para uma transformação do perfil individual: de pessoas submissas e disciplinadas para empreendedoras e independentes (BIANCHI; QUISHIDA, 2009).

Baseado nessas observações, este trabalho buscou descrever as ações de gestão do conhecimento (GC) e as contribuições que esta oferece para a formação da carreira profissional na empresa pesquisada. Para Trindade et al. (2015), as organizações geram conhecimento no transcorrer de seus processos, mas o grande desafio está em administrar este conhecimento ao seu favor, possibilitando benefícios competitivos. Nesse sentido, a utilização da gestão do conhecimento de forma eficaz buscando os conhecimentos existentes na instituição podem trazer fatores positivos para as organizações.

Assim, o estudo apresentado na Associação Brasileira de Recursos Humanos do Rio Grande do Sul (ABRH-RS) procurou investigar as ações de gestão do conhecimento.

\section{REFERENCIAL TEÓRICO}

Conforme Nonaka e Takeuchi (2008), autores referência do tema, no momento em que os negócios modificam-se, as tecnologias multiplicam-se, os concorrentes aumentam e os produtos tornam-se ultrapassados rapidamente, as organiza- 
ções prósperas são as que produzem conhecimentos consistentes e inéditos, os semeiam extensivamente pela empresa e integram velozmente em novos produtos e tecnologias. Ainda segundo Nonaka e Takeuchi (2008 p. 39), “em uma economia onde a única certeza é a incerteza, a fonte certa de vantagem competitiva duradoura é o conhecimento. "

Para Pires (2015), a GC é um modelo que aponta uma série de práticas e processos que pretendem produzir valor para a instituição por intermédio de seus ativos intangíveis. A GC somente é efetiva quando há uma intensa mudança cultural. A GC pode ser visualizada como uma maneira de ampliar o desempenho e o crescimento dos lucros da empresa, se instituído de maneira correta pode servir de modelo de gestão eficaz (RODRIGUES; ALVES, 2010). Chiavenato (2009) acrescenta que não adianta ter capital, é necessário aplicá-lo de maneira rentável. Segundo o autor, os recursos de uma organização são formados de capacidades e ativos empresariais. Os ativos empresariais são talentos que uma instituição agregou como decorrência de investimentos em escala. No entanto, as capacidades intelectuais transmitem coesão entre esses recursos, facilitando assim a criação de vantagem competitiva. Já as capacidades são aglomerados complexos de aprendizados coletivos e habilidades, que favorecem a aplicação de atividades funcionais através de processos empresariais. Neste sentido, a GC torna-se a capacidade determinante da instituição para resultados de vantagens competitivas.

\section{PRÁTICAS DE GESTÃO DO CONHECIMENTO}

Segundo Gaspar et al. (2011), a GC se apoia em estruturadas práticas e processos que buscam melhor gerenciar o recurso conhecimento. Os autores frisam que estas práticas de GC, demostradas no Quadro 1, influenciam na eficácia organizacional da instituição. 
Para Almeida et al. (2016), no cenário da transferência do conhecimento, percebe-se que quanto mais o conteúdo é valioso, mas há dependência da presença física do indivíduo e, quanto mais ela se afasta por meio de tecnologia, mais baixo é a capacidade de transferência com qualidade de informação. Dessa maneira, fica notória a competência dos indivíduos no processo de captação e transformação do conhecimento. Assim, esse processo podo decorrer pela fala, escrita, imagem e gestos. Isto é, a pessoa possui diversas possibilidades de acesso a informação demonstrando que de um mesmo texto podem haver diferentes percepções. Ainda o autor cita algumas práticas de GC demonstradas do Quadro 1.

\section{Quadro 1 - Práticas de Conhecimento}

\begin{tabular}{|c|c|c|}
\hline $\begin{array}{l}\text { Tipo de conhe- } \\
\text { cimento }\end{array}$ & Prática & Descrição \\
\hline Combinação & $\begin{array}{l}\text { Transferên- } \\
\text { cia de co- } \\
\text { nhecimento } \\
\text { explícito }\end{array}$ & $\begin{array}{l}\text { São capacitação aos profissionais da orga- } \\
\text { nização em locais internos ou externos da } \\
\text { empresa com o objetivo de desenvolve-los } \\
\text { tecnicamente ou comportamental. } \\
\text { O objetivo desta prática é que o conheci- } \\
\text { mento explícito seja registrado em um meio } \\
\text { físico através de alguma ferramenta que foi } \\
\text { utilizado durante o projeto, possibilitando o } \\
\text { acesso dessas informações a outras pessoas } \\
\text { da organização em outro momento. }\end{array}$ \\
\hline \multirow{2}{*}{ Externalização } & $\begin{array}{l}\text { Banco de } \\
\text { ideias }\end{array}$ & $\begin{array}{l}\text { Essa prática permite o armazenamento de } \\
\text { ideias de maneira livre se exigir uma análi- } \\
\text { se mais detalhada e avançada. A tecnologia } \\
\text { tem um papel importante nesta prática para } \\
\text { ajudar na categorização das ideias. }\end{array}$ \\
\hline & Narrativas & $\begin{array}{l}\text { Quando há na organização conhecimentos } \\
\text { acumulados através de vivência de alguns } \\
\text { colaboradores que se disponibilizam através } \\
\text { de narrativas externalizar essas experiências } \\
\text { para outros colegas. }\end{array}$ \\
\hline
\end{tabular}




\begin{tabular}{|c|c|c|}
\hline $\begin{array}{l}\text { Tipo de conhe- } \\
\text { cimento }\end{array}$ & Prática & Descrição \\
\hline \multirow{6}{*}{ Internalização } & $\begin{array}{l}\text { Lições } \\
\text { aprendidas }\end{array}$ & $\begin{array}{l}\text { Um momento simples de reflexão final } \\
\text { sobre o projeto pode desenvolver o apren- } \\
\text { dizado. E as respostas obtidas devem serem } \\
\text { armazenadas em um sistema para auxiliar } \\
\text { em consultas futuras. }\end{array}$ \\
\hline & $\begin{array}{l}\text { Rodizio } \\
\text { gerencial }\end{array}$ & $\begin{array}{l}\text { Está prática é comumente vista em organi- } \\
\text { zações grandes, é uma atividade de GC que } \\
\text { busca propiciar aos líderes a oportunidade } \\
\text { de experimentar diversos setores da empresa } \\
\text { obtendo uma visão geral da empresa. }\end{array}$ \\
\hline & $\begin{array}{l}\text { Rodízio } \\
\text { técnico }\end{array}$ & $\begin{array}{l}\text { Através de vivência em períodos curtos em } \\
\text { outras áreas. O objetivo é agilizar o aprendi- } \\
\text { zado dos funcionários em atividades relacio- } \\
\text { nadas, de maneira a obter ou desenvolver os } \\
\text { conhecimentos necessários para o desempe- } \\
\text { nho de suas funções. }\end{array}$ \\
\hline & $\begin{array}{l}\text { Reuniões } \\
\text { de análise } \\
\text { crítica }\end{array}$ & $\begin{array}{l}\text { São reuniões de discussões sobre o que está } \\
\text { acontecendo no projeto com objetivo de apon- } \\
\text { tar possíveis melhorias que agregam valor. } \\
\text { É importante destacar que para ocorrer uma } \\
\text { análise crítica é necessário ter atenção ao todo } \\
\text { do projeto, pois é inviável analisar critica- } \\
\text { mente algo com dados parciais. }\end{array}$ \\
\hline & $\begin{array}{l}\text { Reunião } \\
\text { pós ação }\end{array}$ & $\begin{array}{l}\text { Esta prática, usada pelo Exército, constitui- } \\
\text { se através de uma reunião após a ação para } \\
\text { discutir o que foi planejado e o que foi reali- } \\
\text { zado para avaliar se é passível de mudança } \\
\text { de estratégia no decorrer do projeto. }\end{array}$ \\
\hline & $\begin{array}{l}\text { Transferên- } \\
\text { cia do co- } \\
\text { nhecimento } \\
\text { tácito }\end{array}$ & $\begin{array}{l}\text { Prática que consiste em uma pessoa ou um } \\
\text { grupo que adquiriu o conhecimento através } \\
\text { de uma vivência. Um exemplo bastante uti- } \\
\text { lizado é quando ocorre implantação de um } \\
\text { sistema, onde um grupo de pessoas é treina- } \\
\text { do e depois alocado com colaboradores que } \\
\text { não foram treinados para o compartilhamento } \\
\text { do conhecimento. }\end{array}$ \\
\hline
\end{tabular}




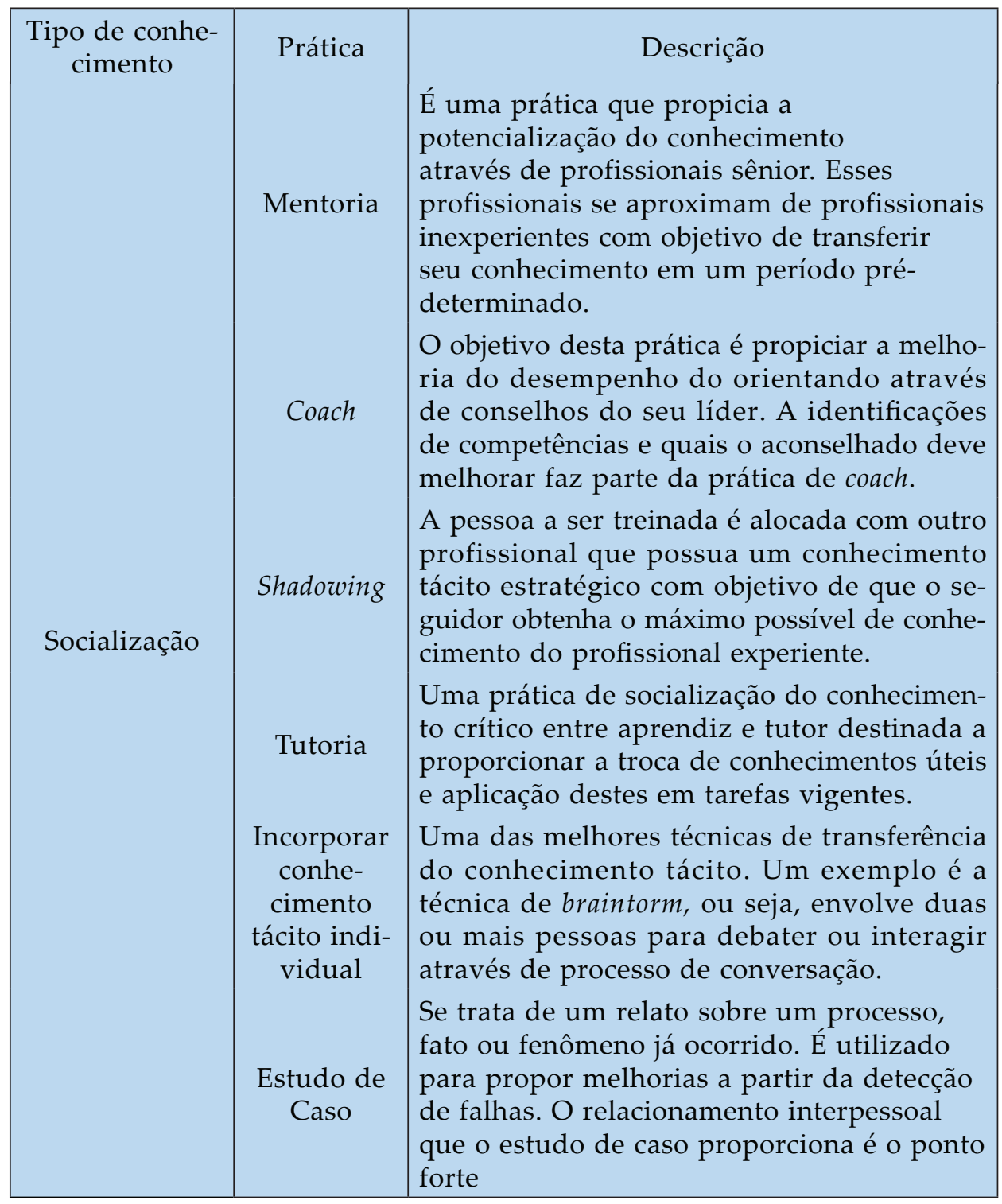

Fonte: Adaptado de Almeida et al. (2016). 


\section{CARREIRA PROFISSIONAL}

Para Fontenelle (2006), o conceito de carreira se modificou ao longo do tempo e essa mudança tem a ver com as transformações no cenário, político, econômicos, sociais e culturais das últimas décadas.

De acordo com o Dutra (2013), se nota a mudança de modelo, onde o foco passa a ser o indivíduo, assumindo o papel principal na condução de sua carreira. A carreira pode ser estabelecida como a sucessão de posições ocupadas no decorrer da vida de um indivíduo, em parte não só dos estudos, trabalhos e experiências de vida, mas também das suas compreensões pessoais, comportamentos e atitudes profissionais que sucedem em evolução de competências para lidar com cenários profissionais de maior complexidade e em permanente transformação (DUTRA, 2013).

Nessa visão, as pessoas passam a serem os protagonistas de maneira global, integrando a vida pessoal com a profissional, transpondo o modelo focado no trabalho para um modelo centrado no indivíduo. Segundo Bendassolli (2009), a carreira não é mais uma continuação relativamente estável de condutas e papéis ocupacionais para englobar os sentidos que as pessoas conferem as suas experiências de trabalho e de vida cada vez mais inconstantes.

Apesar de ser um processo invariável, as carreiras desenvolvem-se com base na evolução no trabalho praticado por profissionais ao decorrer da vida produtiva. O setor de $\mathrm{RH}$ pode apoiar os funcionários com a apresentação clara do papel do emprego e do trabalho e acompanhar o desenvolvimento de cada um. Não é só a área de RH que pode contribuir com a evolução da carreira dos trabalhadores, todos os setores da organização colaboram no desenvolvimento profissional, sempre que instigam seus funcionários a alcançarem metas com comunicação clara e permanente (ADAMI, 2014). 
Segundo Souto (2016), as transformações no universo do trabalho ampliaram a complexidade para dialogar sobre carreira. Os profissionais que estavam ambientados a serem geridos pela organização foram apresentados ao mercado cada vez mais instável e competitivo.

De acordo com Carbone et al. (2009), a competência vai além do conjunto de conhecimentos, habilidades e atitudes fundamentais para desempenhar determinada função, mas também no sentido comportamental e de realizações desinentes da mobilização e aplicação de conhecimentos. Os autores ainda entendem que, as competências humanas são combinações entre conhecimentos habilidades e atitudes, explicitadas através do desempenho profissional incluso no contexto da organização, que acresce valor social e econômico na instituição e no indivíduo.

Ainda segundo os autores Carbone et al. (2009), o conhecimento equivale a informações que, ao serem identificadas e integradas pela pessoa e sua memória, acarretam impacto sobre seu comportamento ou julgamento. Se refere ao saber que o indivíduo adquiri em todo a sua existência. A habilidade se refere à aplicação do conhecimento, isto é, a capacidade de o indivíduo transformar seu conhecimento em ação. Já a atitude, está relacionada aos aspectos relacionais e sociais que irão influenciar na sua conduta em relação às situações, trabalho ou no relacionamento interpessoal.

Figura 1 - Competências como fonte de valor para o indivíduo e a organização

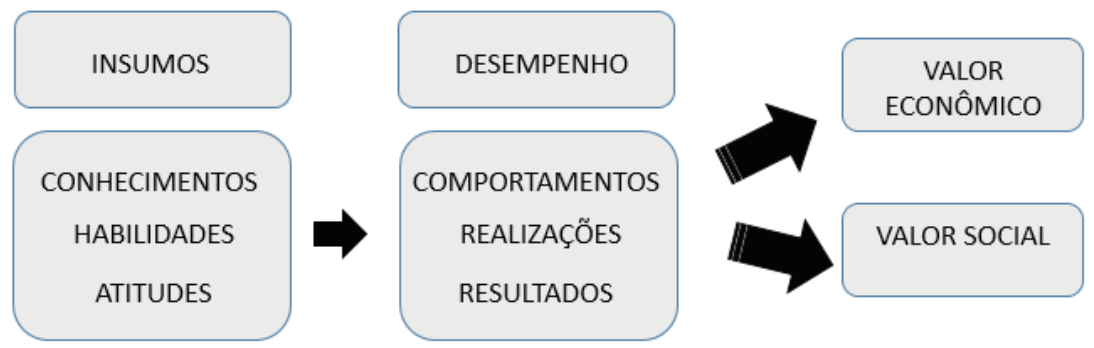

Fonte: Adaptado de Carbone et al. (2009). 
A Figura 2 demonstra que a competência é o resultado da mobilização da pessoa e de um conjunto de recursos e insumos. $\mathrm{O}$ indivíduo expõe a competência quando produz um resultado no trabalho, decorrente da aplicação dos conhecimentos, habilidades e atitudes (CARBONE et al., 2009).

\section{INOVAÇÃO E TECNOLOGIA}

De acordo com Almeida et al. (2016), a inovação abrange inúmeras interpretações dependendo do autor, ambiente, do ator, do mercado, entre outras. Contudo, todas as interpretações tendem a confluir para a geração de algo novo de caráter pessoal, organizacional, intangível ou tangível, mesurável ou não. Em uma visão mais vasta, Meira (2013), inovação é um modelo, é desempenho, é design, é mudança, é poder, é sincronização, é objetivo. Para o autor qualquer inovação é imperfeita, incompleta e não é permanente. Dessa maneira, sempre é possível inovar novamente. Assim, as ações realizadas pelas equipes de trabalho vislumbram o futuro. Neste contexto, ele salienta que inovar depende do conhecimento, de tecnologia, dos clientes e da competição.

Para Almeida et. al. (2016, p. 23), é viável produzir uma cultura de inovação nas empresas com base em processos bem delineados, que irão funcionar como guia e passos a serem seguidos por toda a organização. "Inovação é muito mais do que uma ideia genial a ser adotada por uma empresa."

Na visão da Possoli (2012), a inovação empresarial é um método empresarial voltado para o negócio da instituição, ao sistema de trabalho e as relações externas. A inovação organizacional está relacionada a criação de novas tecnologias para o desenvolvimento de serviços e produtos inovadores, à maneira em que a empresa age no mercado em constante mudança, auxiliando também como diferencial competitivo (FERREIRA; SOUSA, 2008). 


\section{METODOLOGIA}

Esta pesquisa utilizou como procedimento o estudo de caso pois, conforme Yin (2010), o estudo de caso é uma pesquisa empírica que irá investigar um evento atual em profundidade e em seu âmbito real, principalmente quando as fronteiras entre o evento e o contexto não estão explícitas. Para atender aos objetivos desta pesquisa foi utilizado o processo descritivo, pois segundo Barros e Lehfeld (2007), realiza-se a investigação, análise, registro e a interpretação dos eventos do universo físico ligados ao fenômeno do processo pesquisado.

Para abordar o problema proposto, qual a contribuição das ações de gestão do conhecimento na Associação Brasileira de Recursos Humanos na visão dos gestores e colaboradores, foi realizado uma pesquisa de natureza qualitativa, uma vez que buscou as percepções dos gestores da ABRH-RS quanto à gestão do conhecimento. Segundo Gerhardt e Silveira (2009), a pesquisa qualitativa visa o aprofundamento de entendimento de uma comunidade e organização, não se preocupando com a relevância numérica.

Também foi aplicada uma pesquisa de natureza quantitativa para identificar as compreensões acerca das vantagens da GC para a carreira profissional na visão dos colaboradores da empresa estudada. De acordo com Fonseca (2002), na pesquisa de natureza quantitativa os resultados podem ser medidos, diferente dos estudos qualitativos. E, por fim, foi realizada uma pesquisa documental buscando identificar as ações de GC na instituição pesquisada. Para Marconi e Lakatos (2010), na pesquisa documental são utilizados documentos, escritos ou não, caracterizados como fonte primária ou secundárias de informações.

O presente estudo foi realizado na Associação Brasileira de Recursos Humanos na seccional do Rio Grande do Sul, conforme autorização institucional exposta no anexo A, que fica 
AS AÇÕES DE GESTÃo DO CONHECIMENTO PARA A CONSTRUÇÃo

DA CARREIRA PROFISSIONAL NA ASSOCIAÇÃO BRASILEIRA

DE RECURSOS HUMANOS DO RIO GRANDE DO SUL

localizada na cidade de Porto Alegre. Segundo a Associação Brasileira de Recursos Humanos (ABRH, 2017), a associação possui atuação local e é afiliada à ABRH-Brasil, que possui 22 seccionais em diversas regiões do país.

A partir do método de estudo de caso foi realizado uma entrevista com quatro gestores da ABRH-RS dos setores de Educação Corporativa, Marketing, Eventos e Recrutamento e Seleção de Estagiários. Também foi aplicado um questionário direcionado aos colaboradores da Associação Brasileira de Recursos Humanos que hoje conta com 29 funcionários. Quanto a fonte de evidência documental a autora analisou documentos institucionais físicos e digitais que caracterizam práticas de gestão do conhecimento.

Segundo Yin (2010) é fundamental a utilização de diferentes fontes de evidências, como uma triangulação de dados, considerando a teoria, avaliadores e métodos ou perspectivas a fim de explicar as evidências coletadas. $\mathrm{O}$ autor ainda comenta que o uso de várias fontes de evidências tende a diminuir os erros de análise de dados. Foi feito uma triangulação dos dados e as técnicas de análises foram interpretativas e estatística. A pesquisadora utilizou-se de uma ferramenta visual, mapa de empatia adaptado, para demostrar as três técnicas de coleta de dados em um único modelo, a fim de agrupar e facilitar a compreensão dos resultados obtidos na pesquisa.

\section{ANÁLISE E DISCUSSÃO DOS RESULTADOS}

Para a pesquisa quantitativa, foram entregues 29 questionários, exposto no apêndice $\mathrm{B}$, obtendo cem por cento de respostas. A coleta de dados ocorreu mês de julho de 2017. Para análise, a pesquisadora dividiu as perguntas em dois blocos, perfil dos respondentes e práticas de gestão do conhecimento.

Com base no perfil dos colaboradores da ABRH-RS, a empresa valoriza os profissionais que investem na sua forma-

REMAS • Revista Metodista de Administração do Sul, v. 2, N. 2, 2017 
ção acadêmica já que $86,2 \%$ dos funcionários está buscando a graduação, já terminou ou está cursando a pós-graduação. Relacionando com a teoria, Chiavenato (2009), afirma que a vantagem competitiva está atrelada as capacidades intelectuais da instituição, e essas capacidades devem transmitir coesão entre seus recursos. Ou seja, o capital intelectual deve estar preparado e em constante aprimoramento. Outro ponto importante no perfil dos colaboradores da ABRH-RS é que se percebe uma valorização dos estagiários, já que $41 \%$ dos funcionários que tiveram a oportunidade de atuar em outra função na organização, eram estagiários e foram efetivados. Carvalho (2012) indica que o capital intelectual é fundamental para a gestão do conhecimento, porque são as pessoas que detém a capacidade de aprender, criar e compartilhar o conhecimento.

Com base nas práticas de gestão do conhecimento reconhecidas pelos profissionais da ABRH-RS, percebe-se que os funcionários valorizam e reconhecem os eventos e treinamentos ofertados na instituição. Também entre as ações de conhecimento se destacam como auxílio no desenvolvimento na carreira profissional: reuniões, mentorias e feedback. Os funcionários apontaram que reconhecem a remuneração como fator importante para a motivação no trabalho, porém valorizam a instituição pelo conhecimento agregado através das ações promovidas. Outro indicador demonstrado na pesquisa é que os profissionais percebem em partes a troca de conhecimento, embora eles reconheçam as ações realizadas pela instituição, mas não associam como ações de conhecimento. Ou seja, a instituição promove as ações de conhecimento, os funcionários reconhecem, mas não conseguem identificar como fator de GC. Trazendo para a teoria, a GC e a inovação caminham em conjunto, pois para haver inovação, se faz necessário uma cultura de gestão com base no conhecimento para melhoria contínua (ALMEIDA et al., 2016). Isto é, não está evidente 
AS AÇÕES DE GESTÃo DO CONHECIMENTO PARA A CONSTRUÇÃo

DA CARREIRA PROFISSIONAL NA ASSOCIAÇÃO BRASILEIRA

DE RECURSOS HUMANOS DO RIO GRANDE DO SUL

para os funcionários da instituição, a cultura voltada para o conhecimento.

O período utilizado para a análise documental iniciou no mês de agosto de 2017, a pesquisadora, por ser funcionária da instituição, teve acesso aos documentos físicos como: atas e manuais, ao site e a intranet da ABRH-RS, empresa pesquisada.

Com relação as práticas de reuniões de líderes e de equipes utilizadas pela ABRH-RS, foram observados os seguintes processos. Há uma reunião mensal chamada gestão compartilhada. Os líderes da empresa se reúnem com o objetivo de compartilhar e discutir as ações de cada área e também explanado sobre os acontecimentos de cada setor e suas melhores práticas e inovações. Esta reunião é documentada e os líderes podem ter acesso através da intranet. Também há uma reunião mensal, chamada Reunião de Plano de Ação. Esta reunião ocorre com as áreas individuais mediadas pela a gerente e o superintendente da empresa. Nesta reunião são discutidas as ações do mês anterior e comparadas com a estratégia da área e discutidas as ações do próximo mês. As reuniões de equipe, são bem diversificadas. Cada líder de setor é responsável por formatar a dinâmica da reunião com sua equipe, e esta prática não costuma ser documentadas por todos os gestores, mas alguns líderes salvam suas apresentações em slides na intranet de cada setor. Este documento não fica disponível para acesso de outras áreas da organização, a menos que seja solicitado ao líder de cada área. As reuniões acima citadas são práticas de gestão do conhecimento alinhadas com a teoria de Almeida et al.(2016), que aponta a importância das reuniões de análise crítica de pós ação, onde os indivíduos fazem uma análise sobre o que foi praticado para verificação possíveis melhorias e agregar e agregar valor aos projetos futuros. Outro ponto relevante a se observar, e que salienta Meira (2013), são as ações de

ReMas - Revista Metodista de Administração do Sul, v. 2, N. 2, 2017 
inovação que dependem do conhecimento e da competição geradas nas equipes com visão no futuro.

De acordo com o site da instituição a ABRH-RS (2017) são oferecidos treinamentos e eventos voltados para liderança e recursos humanos para o público externo. Os funcionários podem ter acesso a esses cursos e eventos de maneira gratuita, mas devem obedecer algumas regras. O funcionário deve estar no mínimo há três meses na instituição e a capacitação deve ser analisada e autorizada pelo líder direto de cada setor. O interessado apresenta a solicitação de curso assinado pelo líder da área e entrega para a coordenadora de RH. Este documento fica arquivado com a área de recursos humanos, que irá inscrever o colaborador no desenvolvimento solicitado. O setor de educação corporativa tem uma peculiaridade em relação aos outros setores, os cursos são parte do treinamento. Neste caso, os funcionários desta área não necessariamente obedecem a regra dos três meses mínimos da instituição e, assim, que entram na organização, já estão autorizados a realizarem os cursos. As apresentações dos cursos estão disponíveis no site da ABRH-RS. Neste sentido a organização consegue aproveitar um produto que traz rentabilidade financeira e também desenvolve seus colaboradores através dos cursos e eventos. Esta prática corrobora com a teoria de Chiavenato (2009), onde ele salienta que a administração deve utilizar os recursos existente na instituição a fim de desenvolver seus recursos humanos gerando valor a instituição. Para Almeida et al. (2016), o treinamento é uma prática de conhecimento que oportuniza aos colaboradores um desenvolvimento comportamental ou técnico.

A mentoria é uma atividade utilizada na instituição, mas não de maneira geral. Não são todas as áreas que se utilizam desta ferramenta de conhecimento. Segundo Almeida et al. (2016), a mentoria é uma prática que potencializa o conhe- 
AS AÇÕES DE GESTÃo DO CONHECIMENTO PARA A CONSTRUÇÃo

DA CARREIRA PROFISSIONAL NA ASSOCIAÇÃO BRASILEIRA

DE RECURSOS HUMANOS DO RIO GRANDE DO SUL

cimento através de um funcionário sênior que faz a transferência deste conhecimento para um profissional com menos experiência. A área da instituição que utiliza esta prática é: Recrutamento e seleção, que nomeia esta prática como madrinha e contratos, onde tem uma profissional sênior que se responsabiliza por este treinamento. Outra técnica utilizada é o brainstorm, está prática é utilizada entre equipes que tem um maior contato, mas não é utilizada com todas as equipes ao mesmo tempo. Se pode citar o exemplo das equipes de contratos e de recrutamento e seleção. Estas equipes interagem com as clientes em momentos diferentes, mas uma depende da outra. Então, necessita de um alinhamento afinado para não haver falhas no processo. Há reuniões periódicas entre equipes e assim se utilizada da prática de brainstorm para criação e compartilhamento de conhecimento. É uma técnica que proporciona um debate e interação entre os envolvidos através de um processo de conversação (ALMEIDA ET AL., 2016).

As narrativas são utilizadas na $\mathrm{ABRH}-\mathrm{RS}$, porém não são processos formais e a maioria não é documentada. Este processo ocorre sempre que há um projeto novo e o líder da área responsável por o novo projeto conversa com o gerente ou superintendente. Segundo Dalkir (2005) o compartilhamento e aperfeiçoamento do conhecimento empresarial se deve aos ensinos e aprendizados do passado, assim buscando aprender com seus erros do passado e valorizando o reuso dos conhecimentos existentes gerando inovação. Nesta mesma linha de raciocínio Almeida et al. (2016) reitera que as narrativas são oportunidades de externalização de experiências para outras pessoas.

A empresa disponibiliza de um sistema de informação. A ABRH-RS optou por ter uma área de tecnologia que desenvolveu um sistema próprio. Este sistema começou a ser implantado em 2017 e está em fase de ajustes, pois a empresa definiu prioridades para implantação por módulos. O cronograma de

ReMas - Revista Metodista de Administração do Sul, v. 2, N. 2, 2017 
implantação do sistema prevê que até o final de 2018 todas as áreas já estejam contempladas com o sistema que atendam suas necessidades. Neste sentido, a ABRH-RS encontra-se atrasada em relação ao mercado, já que o sistema atual não abrange todas as áreas, podendo perder informações e por consequência conhecimento até o término da implantação. De acordo com Wagner Werner e Ilvini Werner (2004), a tecnologia da informação é uma importante ferramenta para sustentar o negócio desenvolvendo métodos de armazenamento e, assim, pode gerar transferência de conhecimento.

Por fim, o objetivo específico alcançado com a pesquisa documental foi descrever as contribuições das ações de conhecimento na ABRH-RS. As ações descritas e alinhadas com a teoria de Almeida et al. (2016) e Nonaka e Takeuchi (1997), foram: reuniões, treinamentos, mentoria, brainstorm, narrativas e sistema de informação.

$\mathrm{Na}$ análise qualitativa, as entrevistas foram realizadas no período de junho a setembro de 2017, na sede da ABRH-RS, com horários pré-agendados com os líderes. Foram entrevistas com objetivo de entender os processos de gestão de conhecimento utilizado pela empresa, além de entender as percepções dos gestores em relação as práticas de Gestão do Conhecimento. Foram entrevistados 4 gestores das áreas de educação corporativa, recrutamento e seleção, marketing e eventos.

A primeira entrevistada foi a gestora da área de educação corporativa, formada em pedagogia e com pós-graduação em educação corporativa em andamento, e a entrevista ocorreu no dia 28 de junho de 2017. A segunda entrevistada foi a líder da área de recrutamento e seleção, formada em pedagogia com pós-graduação em gestão de recursos humanos, e esta entrevista foi realizada no dia 18 de julho de 2017. O terceiro entrevistado foi o gestor da área de marketing, formado em publicidade de propaganda e com pós-graduação em mídias sociais em andamento, e a entrevista foi realizada no dia 20 
AS AÇÕES DE GESTÃo DO CONHECIMENTO PARA A CONSTRUÇÃo

DA CARREIRA PROFISSIONAL NA ASSOCIAÇÃO BRASILEIRA

DE RECURSOS HUMANOS DO RIO GRANDE DO SUL

de julho de 2017. A última entrevistada foi a gestora da área de eventos, formada em relações públicas, e a entrevista ocorreu no dia 04 de setembro de 2017. A pesquisadora gravou as entrevistas para posterior transcrição e utilizou o roteiro semiestruturado.

Inicialmente foi questionado aos entrevistados sobre o conceito de gestão do conhecimento em relação ações cotidianas percebidas na organização, que segundo Pires (2015) são modelos de práticas de processos que buscam agregar valor à organização através de seus bens intelectuais. Dos quatro entrevistados, três responderam positivamente quanto a percepção de ações na organização pesquisada. Vale destacar que os três entrevistados que responderam que enxergam na instituição ações de GC salientaram que reconhecem as práticas, mas de maneira informal. O ponto em que empresa deveria melhorar é o não hábito de documentar todas as práticas realizadas na instituição para acesso futuro, pois segundo os entrevistados algumas processos e práticas são documentados e outros não. Outro ponto que é congruente entre os quatro entrevistados é que a gerente geral é reconhecida como principal fonte de conhecimento da organização. Como pessoa referência em conhecimento. Observa-se um desacordo com a teoria de Teixeira Neto (2016), que salienta que as ações geradas nas organizações devem ser todas documentadas e expandidas para toda a organização para que haja uma gestão do conhecimento eficaz.

O foco dos questionamentos seguintes foi em relação as práticas de gestão do conhecimento utilizadas na organização. Nas reuniões de ação e pós projeto todos os entrevistados consideram as reuniões entre líderes e entre equipes importantes para o desenvolvimento e aprimoramento dos projetos. Mostrando que a empresa está alinhada com a teoria de Nonaka e Takeuchi (2008) e Almeida et al. (2016), eles trazem que as reuniões são importantes ferramentas de construção

ReMAS - Revista Metodista de Administração do Sul, v. 2, N. 2, 2017 
e transmissão de conhecimento. Foram citadas por todos os entrevistados a reunião de Plano de Ação. Esta reunião é realizada entre equipe e gerência, mensalmente, e tem como objetivo principal a discussão dos projetos em andamento e o aprimoramento das ações vinculadas neste projeto. Outra reunião citada pelos líderes foi a de Indicadores de Gestão Compartilhada (ICG) - esta reunião é somente dos líderes e o objetivo é compartilhar os indicadores de cada setor e as ações de cada gestor e obter troca de conhecimento. Embora haja uma unanimidade sobre a importância da reunião de ICG, também houve algumas observações quanto a pontos de melhoria para esta prática.

Ainda sobre as práticas de GC utilizadas na instituição - uma prática que houve o reconhecimento de uma maneira geral foi os treinamentos. Todos os líderes entrevistados passaram pelo o desenvolvimento de lideranças. E os funcionários podem realizar os treinamentos oferecidos pela instituição, além de participarem dos eventos: fórum, palestras, congresso de RH e prêmios. Neste sentido, a empresa demostra que disponibiliza aos seus funcionários diversos treinamentos que possibilitam o desenvolvimento do conhecimento tácito e explícito conforme Nonaka e Takeuchi (1997).

Em relação as estratégias utilizadas pelos gestores para enfrentar os desafios na organização utilizando o capital intelectual da organização, os líderes concordam que quando um desafio é enfrentado é necessário o compartilhamento de ideias entre equipes através de reuniões, onde se utilizada a técnica de brainstorm para explorar o conhecimento individual, conforme orienta Cisne, Kaneoya e Santos (2015). Também os líderes percebem um ambiente favorável entre eles para troca de informações, embora essa troca de informações seja de maneira informal. Existe uma cultura colaborativa entre os líderes que busca fomentar o conhecimento buscando melhorias para a organização, conforme ressalta Dorfey e Frozza (2015). 
AS AÇÕES DE GESTÃo DO CONHECIMENTO PARA A CONSTRUÇÃo

DA CARREIRA PROFISSIONAL NA ASSOCIAÇÃO BRASILEIRA

DE RECURSOS HUMANOS DO RIO GRANDE DO SUL

Por fim, o questionamento aos entrevistados foi em relação as suas percepções das ações do conhecimento da ABRH-RS em relação a formação da sua carreira profissional e de seus liderados. Todos os entrevistados concordam que há um desenvolvimento profissional através das ações promovidas pela ABRH-RS. Em destaque estão os treinamentos, oportunidade de participação nos eventos que a instituição promove e o contato com a diretoria e conselho que são formados por profissionais com um bom posicionamento e experiência no mercado. Se percebe uma valorização aos bens intangíveis da organização conforme salienta Machado et al. (2015).

\section{SÍNTESE DOS RESULTADOS DA PESQUISA}

A pesquisadora buscou uma ferramenta visual para consolidar os resultados das três técnicas de coleta de dados utilizadas na pesquisa: questionário, entrevista e pesquisa documental. A ferramenta visual adaptada para a realidade da pesquisa foi o mapa de empatia. Através do mapa foi possível compreender cada um dos seis seguimentos da ferramenta: o que pensa, vê, escuta, fala e faz, os desafios e os objetivos, fazendo uma analogia para a realidade do assunto pesquisado pela ótica dos respondentes (SOUZA; DANILEVICZ, 2014).

A Figura 2 demonstra que os funcionários de uma maneira geral valorizam, reconhecem e praticam as ações de gestão do conhecimento. Eles enxergam, com isso, um desenvolvimento de suas competências profissionais. Embora eles concordem em partes com a troca de conhecimento e percebem a gestão do conhecimento de maneira informal na organização pesquisada. Os funcionários identificam uma valorização do capital intelectual através dos treinamentos, mas a remuneração é apontada como fator que mais os motiva para a busca de novos conhecimentos. Como cenário ideal, a ABRH-RS deveria documentar todas as ações de conhecimento realizadas na organização para acesso futuro e base para inovações (SMEDLUND, 2009). 
REMIAS

REVISTA METODISTA DE ADMINISTRAÇÃO DO SUL

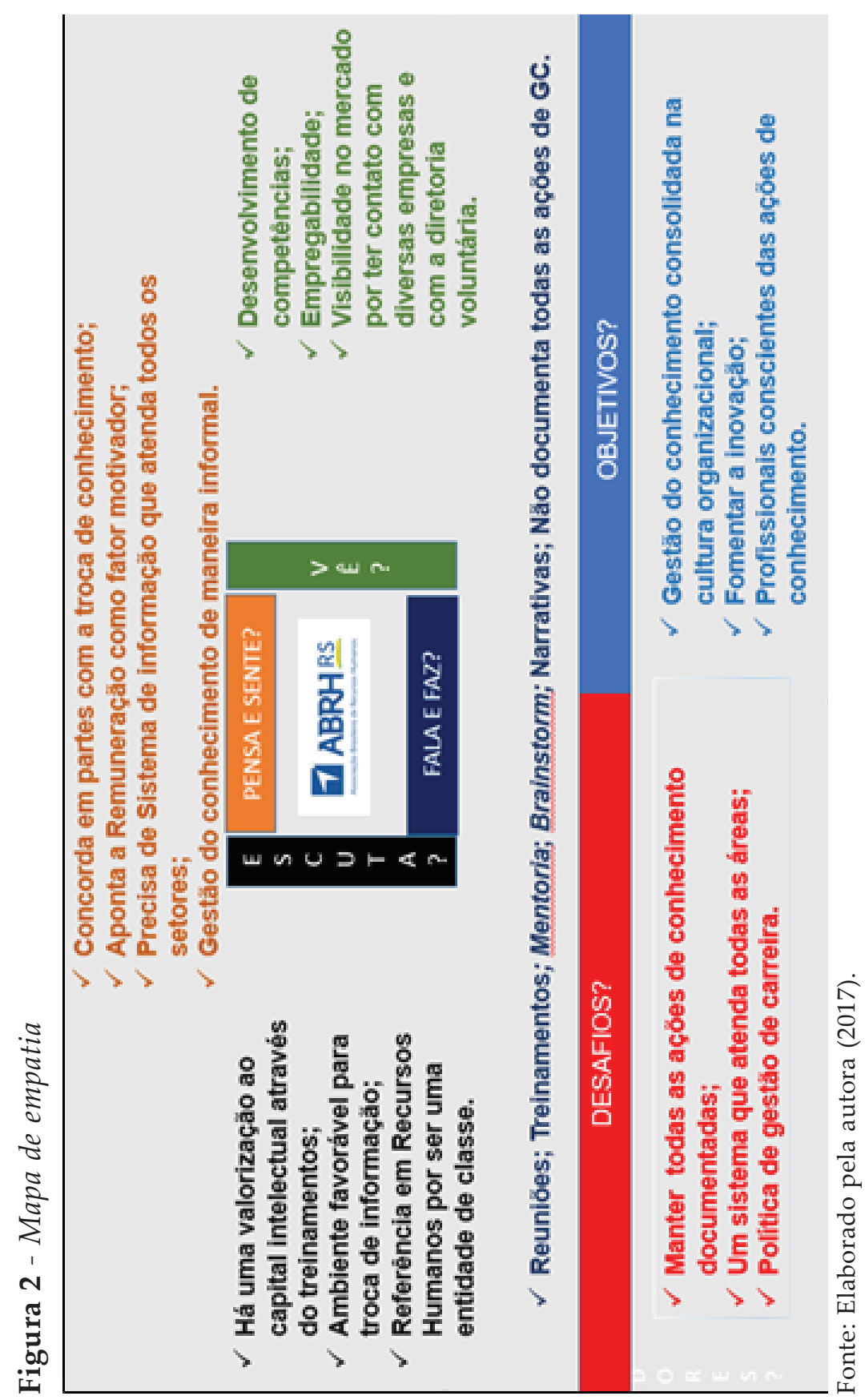

56 Remas • Revista Metodista de Administração do Sul, v. 2, N. 2, 2017 


\section{CONSIDERAÇÕES FINAIS}

O presente trabalho teve como objetivo identificar as ações de gestão do conhecimento na ABRH-RS na construção da carreira profissional de seus gestores e funcionários.

Para atingir o objetivo proposto optou-se pelo método de estudo de caso, pois a presente pesquisa faz parte âmbito real da empresa (YIN, 2010). A natureza da pesquisa foi descritiva com três fontes de evidências: questionário, documental e entrevistas. Esta escolha justifica-se pela busca das percepções dos profissionais sobre as ações de gestão do conhecimento e sua carreira profissional.

Para esclarecer o objetivo geral deste trabalho foram estipulados três objetivos específicos. O primeiro objetivo específico foi descrever as ações de GC na instituição pesquisada. Por meio da análise documental foi possível identificar as ações de gestão do conhecimento utilizadas na ABRH-RS. Dentre as ações estão, treinamentos, eventos, reuniões de pós ação e análise crítica, mentoria, brainstorm e narrativas. São práticas de gestão do conhecimento que fomentam a aprendizagem organizacional e a inovação em seus processos, conforme salienta (SMITH; COLLINS; CLARK, 2005; ALMEIDA et al., 2016).

O segundo objetivo específico buscou discutir a relevância da gestão do conhecimento na ABRH-RS na visão do gestor. Por meio das entrevistas com os líderes das áreas de Educação Corporativa, Seleção, Marketing e Eventos se pode perceber que há um reconhecimento e valorização das ações de práticas de conhecimento utilizadas pela organização. As práticas de gestão do conhecimento citadas pelos respondentes são: reuniões, treinamentos, brainstorm e narrativas. Estas práticas auxiliam no desenvolvimento técnico e comportamental, influenciam positivamente na dinâmica operacional e no clima organizacional. Neste sentido, a organização se aproxima da teoria de Pires (2015), a gestão do conhecimento é voltada 
para o capital intelectual, ou seja, são práticas que valorizam as pessoas através do gerenciamento do conhecimento da organização. Além disso, pode-se perceber que de uma maneira geral, entre os líderes, as práticas de GC são utilizadas de maneira informal, isto é, as ações não são todas documentadas. Neste sentido, a teoria aconselha que o conhecimento gerado na organização seja documentado para que possa ser compartilhado no futuro e assim administrado (CHIAVENATO, 2009).

Com relação à carreira profissional, a percepção dos líderes é que a instituição oferece oportunidade de desenvolvimento na carreira através das ações de gestão de conhecimento, mas que há uma limitação de crescimento na remuneração e de cargos. Neste sentido, a empresa investe no capital intelectual através dos treinamentos e de fomentar as práticas de troca de conhecimento, mas não tem uma política eficaz remuneratória e não faz a gestão cargos e salários. Para Almeida et al. (2016), as instituições enfrentam um desafio em construir uma política de gestão de cargos e salários que seja eficaz e fomentem a motivação de seus profissionais.

O terceiro objetivo específico foi destinado a averiguar as vantagens da GC para a carreira profissional dos colaboradores na empresa estudada. Os profissionais da instituição reconhecem como fator importante na construção de suas carreiras, as ações utilizadas na organização. Dentre as ações em destaque na pesquisa, estão: reuniões, treinamentos, mentoria e estudo de caso. A empresa não tem um plano formal de gestão de carreira, mas investe em desenvolvimento através das capacitações. Os funcionários da ABRH-RS enaltecem este posicionamento da instituição quando reconhecem como fatores importantes para suas carreiras, o desenvolvimento de competência e a empregabilidade. Os profissionais da empresa apontam que a remuneração é um fator importante motivacional, mas não é o fator determinante para manter-se 
na organização. Neste sentido, a qualidade de vida no trabalho aparece como o segundo elemento que os motivam para o desenvolvimento na empresa. Também, a pesquisa evidencia que os funcionários valorizam o ambiente organizacional e a empregabilidade. A teoria de Malschitzy (2012), indica que o profissional moderno busca o aprimoramento constante de suas competências para estar preparado para uma possível recolocação no mercado, se necessário.

A pesquisadora enfrentou algumas limitações para a coleta dos dados das entrevistas, em função das agendas dos gestores. Outro ponto a destacar é que a pesquisadora é funcionária da instituição, portanto, ela teve que manter a imparcialidade na coleta e análise dos resultados, não permitindo que seus conhecimentos prejudicassem os resultados da pesquisa.

No sentido dos benefícios para a pesquisadora, a oportunidade de aplicar os conhecimentos teóricos em confronto com a realidade da organização pesquisada contribui para a formação profissional da pesquisadora, além desta pesquisa, ser fundamental para sua formação acadêmica. Também contribui para a empresa na qual trabalha através de um diagnóstico que pode ser utilizado como indicador para melhorias futuras.

No que tange o aperfeiçoamento dos resultados alcançados neste estudo, a pesquisadora sugere uma pesquisa com a diretoria da associação. Embora a diretoria seja voluntária, ela é responsável pela estratégia da instituição, podendo sugerir possíveis melhorias nos processos de gestão do conhecimento da organização.

Por fim, esta pesquisa conclui que as ações de gestão do conhecimento utilizadas pela ABRH-RS contribuem para a formação da carreira profissional de seus colaboradores, tendo em vista que a empresa investe em desenvolvimento das competências dos profissionais, através dos treinamentos, dos incentivos de utilização das práticas de GC e dá liberdade para 
implantação de diferentes ferramentas de gestão de conhecimento, assim fechando o ciclo das competências.

\section{REFERÊNCIAS}

ASSOCIAÇÃO BRASILEIRA DE RECURSOS HUMANOS (ABRH). Sobre a ABRH-RS: Quem Somos. Porto Alegre. 2017. Disponível em: <http://www. abrhrs.org.br/a-abrh/quem-somos>. Acesso em: 10 maio. 2017.

ADAMI, Elisabete. Gestão de Talentos. São Paulo: Pearson Education do Brasil, 2014.

ALMEIDA; Alvinio et al. Inovação e Gestão do Conhecimento. Rio de Janeiro: Editora FVG, 2016.

BARROS, Aidil Jesus da Silveira; LEHFELD, Neide Aparecida de Souza. Fundamentos de metodologia científica. São Paulo: Atlas, 2007.

BENDASSOLLI, Pedro F. Recomposição da relação sujeito-trabalho nos modelos emergentes de carreira. RAE-Revista de Administração de Empresas, v. 49, n. 4, p. 387-400, 2009.

BIANCHI, Elaine Maria Pires Giavina; QUISHIDA, Alessandra. Gestão estratégica de carreiras. In: ALBURQUERQUE, Lindolfo Galvão; LEITE, Nildes Pitombo. Gestão de pessoas: perspectivas estratégicas. São Paulo: Atlas, 2009. p. 55-70.

CARVALHO, Fabio. Gestão do conhecimento. São Paulo: Pearson Education do Brasil, 2012.

CARBONE, Pedro Paulo; BRANDÃO, Hugo Pena; LEITE, João Batista Diniz. Gestão por competências e gestão do conhecimento. Rio de Janeiro: FGV, 2009.

CHIAVENATO, Idalberto. Recursos Humanos: o capital humano das organizações. 9. ed. Rio de Janeiro: Elsevier, 2009.

CISNE, Caroline S.; KANEOYA, Paula H.; SANTOS, Luana C. M. Compartilhamento e registro de conhecimento: um estudo de caso na empresa knowtec. Revista ACB: Biblioteconomia em Santa Catarina, Florianópolis, v. 20, n. 1, p. 98-111, jan./abr., 2015. Disponível em: <https://dialnet.unirioja. es/descarga/articulo/5026071.pdf >. Acesso em: 01 de out. 2016.

DALKIR, Kimiz. Knowledge management in theory and practice. Burlington:Elsevier, 2005. 
AS AÇÕES DE GESTÃo DO CONHECIMENTO PARA A CONSTRUÇÃo

DA CARREIRA PROFISSIONAL NA ASSOCIAÇÃO BRASILEIRA

DE RECURSOS HUMANOS DO RIO GRANDE DO SUL

DORFEY, Dáila Elisa; FROZZA, Rejane. O uso da gestão do conhecimento no processo de avaliação de cursos de graduação. Perspectivas em Ciência da Informação, v. 20, n. 1, p. 120-137, 2015.

DUTRA, Joel Souza et al. As Carreiras inteligentes e sua percepção pelo clima organizacional. Revista Brasileira de Orientação profissional, v. 10, n. 1. jun. 2009. Disponível em: <http://pepsic.bvsalud.org/pdf/rbop/v10n1/ v10n1a08.pdf>. Acesso em: 19 de mar. 2017.

DUTRA, Joel Souza; VELOSO, Elza Fátima Rosa. Desafios da Gestão de Carreira. São Paulo: Atlas, 2013.

FONSECA, J. J. S. Metodologia da pesquisa científica. [Apostila] Fortaleza: UEC, 2002.

FONTENELLE, Isleide Arruda. Autogestão estratégica de carreira. São Paulo HSM Management Update, n. 31, paginação irregular, abril 2006. Disponível em: <http://gvpesquisa.fgv.br/sites/gvpesquisa.fgv.br/files/arquivos/fontenelle_-_autogestao_estrategica_de_carreira.pdf>. Acesso em: 07 de out. 2016.

GASPAR, Marcos Antonio et al. A influência das práticas de Gestão do Conhecimento na Eficácia Organizacional: um estudo em Empresas atuantes na Indústria de Software no Brasil. Revista Espacios, v. 33, n. 3, paginação irregular, 2011. Disponível em: <http://www.revistaespacios.com/ a12v33n03/123303191.html>. Acesso em: 01 maio. 2017.

GERHARDT, Tatiana Engel; SILVEIRA, Denise Tolfo. Métodos de Pesquisa. Porto Alegre: Editora da UFRGS, 2009.

GRAMIGNA, Maria. Modelo de competências e gestão dos talentos. São Paulo: Makron Books, 2002.

MARCONI, Maria de Andrade; LAKATOS, Eva Maria e. Fundamentos de Metodologia Científica. 5. ed. São Paulo: Atlas, 2003.

MALSCHITZKY, Nancy. A importância da orientação de carreira na empregabilidade. Revista da FAE, v. 15, n. 1, p. 150-165, 2012.

MEIRA, Silvio. Novos negócios inovadores de crescimento empreendedor no Brasil. Rio de Janeiro: Casa da Palavra, 2013.

NONAKA, Ikujiro; TAKEUCHI, Hirotaka. Criação de conhecimento na empresa: como as empresas japonesas geram a dinâmica da inovação. 20 ed. Rio de Janeiro: Elsevier, 1997.

NONAKA, Ikujiro; TAKEUCHI, Hirotaka. Gestão do conhecimento. São Paulo: Bookman, 2008. 
PIRES, Camila. O essencial da gestão do conhecimento. Rio de Janeiro: Índigo, 2015. Disponível em: <http://redeindigo.com.br/wp-content/uploads/2015/02/REDE-INDIGO-EBOOK-O-ESSENCIAL-DA-GEST\%C3\%83O-DO-CONHECIMENTO.pdf>. Acesso em: 01 out. 2016.

RICARDO, Eleonora. Gestão da educação corporativa. São Paulo: Pearson, 2007.

RODRIGUES, Wiliam D. G. R.; ALVES, Rozane. Gestão do conhecimento: uma análise de como o conhecimento é utilizado pela empresa pvcbrazil - tubos e conexões como forma de inovação e competitividade. Facesi em revista, v. 2, n. 2, p. 2-17, 2010. Disponível em: <http://www.facesi.edu.br/ facesiemrevista/downloads/numero4/artigo03.pdf>. Acesso em: 20 out. 2016.

SMEDLUND, Anssi. Social network structures for explicit, tacit and potential knowledge. International Journal of Knowledge Management, v. 5, n. 1, p. 78-87, 2009.

SMITH, Ken G.; COLLINS, Christopher J.; CLARK, Kevin D. Existing knowledge, knowledge creation capability, and the rate of new product introduction in high-technology firms. Academy of management journal, v. 48, n. 2, p. 346-357, 2005.

SOUTO, Rafael. Mais do que avaliar desempenho é preciso dialogar sobre carreira. Valor Econômico, São Paulo, 15 set. 2016. Economia. Disponível em: $<$ http://www.valor.com.br/carreira/4710415/mais-do-que-avaliar-desempenho-e-preciso-falar-sobre-carreira>. Acesso em: 11 nov. 2016.

SOUZA, Amanda Latosinski Santos de. Concepção de modelo de negócio de startup: um estudo sobre a aplicação do modelo de desenvolvimento de clientes. 2014. 14 f. Trabalho de Conclusão de Curso (Graduação) - Universidade Federal do Rio Grande do Sul, Porto Alegre, 2014.

TRINDADE, Evelin Priscila et al. Análise do processo de gestão do conhecimento em uma empresa de base tecnológica da cidade de Joinville-SC. Navus, Florianópolis, v. 5, n. 3, p. 102-111, jul./set. 2015. Disponível em: $<$ http://navus.sc.senac.br/index.php/navus/article/download/257/242>. Acesso em: 09 set. 2016.

VELOSO, Elsa Fátima Rosa; SILVA, Rodrigo Cunha da; DUTRA, Joel Souza. Diferentes gerações e percepções sobre carreiras inteligentes e crescimento profissional nas organizações. Rev. Bras. Orientac. Prof., v. 13, n. 2, p. 197-208, 2012. Disponível em: <http://pepsic.bvsalud.org/scielo. php?script=sci_arttext\&pid=S1679-33902012000200007\&lng=pt\&nrm=iso $>$. Acesso em: 28 ago. 2016.

YIN, R. Estudo de caso: planejamento e métodos. Porto Alegre: Bookman, 2010. 